\title{
Effect of Annealing on Strain-Temperature Response under Constant Tensile Stress in Cold-Worked NiTi Thin Wire
}

\author{
Xiaojun Yan and Jan Van Humbeeck \\ Department of Metallurgy and Materials Engineering, K.U. Leuven, Kasteelpark Arenberg 44, Bus 2450, 3001 Heverlee, Belgium \\ Correspondence should be addressed to Jan Van Humbeeck, jan.vanhumbeeck@mtm.kuleuven.be
}

Received 17 November 2010; Accepted 6 January 2011

Academic Editor: Yanjun Zheng

Copyright ( $) 2011$ X. Yan and J. Van Humbeeck. This is an open access article distributed under the Creative Commons Attribution License, which permits unrestricted use, distribution, and reproduction in any medium, provided the original work is properly cited.

\begin{abstract}
The present paper aims to understand the influence of annealing on the strain-temperature response of a cold-worked NiTi wire under constant tensile stress. It was found that transformation behavior, stress-strain relationship, and strain-temperature response of the cold-worked NiTi wire are strongly affected by the annealing temperature. Large martensitic strains can be reached even though the applied stress is below the plateau stress of the martensite phase. At all stress levels transformation strain increases with increasing annealing temperature in the range of $350^{\circ}-450^{\circ} \mathrm{C}$ and decreases with increasing annealing temperature in the range of $450^{\circ}-650^{\circ} \mathrm{C}$. The martensitic strain at lower stress levels exhibits the same tendency. At higher stress levels the martensitic strain increases with increasing annealing temperature.
\end{abstract}

\section{Introduction}

Among many shape memory alloys (SMAs), NiTi has been widely used in many technological and engineering applications due to its excellent shape memory effect, superelasticity, high damping capacity, and others $[1,2]$. Its remarkable properties result from a reversible martensitic phase transformation between austenite (B2) and martensite (B19') phases, which can be either stress induced or temperature driven. The transformation is sensitive to factors such as material composition, deformation processing, and heat treatments. Therefore, a mix of cold work followed by a specific annealing process has been comprehensively considered to optimize the physical and mechanical properties of a NiTi product and achieve shape memory and/or superelasticity. Significant efforts have been made to address the effects of heat treatment on transformation behavior [3-5], microstructure $[6-8]$, recovery stress $[9,10]$, damping $[11,12]$, plateau stress and strain $[13,14]$, as well as lifetime of NiTi SMAs $[15,16]$.

To open new applications of NiTi SMAs, including smart structures, intelligent controllers, and memory devices, the understanding of strain and phase transformation behavior under constant applied stress is essential.
In the present paper the influence of annealing on martensitic transformation and residual strains of coldworked NiTi wire developed during cooling/heating under constant tensile stress has been investigated.

\section{Experimental Procedure}

The experiments were performed on a commercial NiTi wire provided by SAES Getters (Italy) with a diameter of $0.076 \mathrm{~mm}$ and a normal composition of 50.2 at \% Ni. Asreceived wires (35\% cold-worked) with a length of $100 \mathrm{~mm}$ were annealed in an argon atmosphere for $10 \mathrm{~min}$ at $350^{\circ}$, $450^{\circ}, 550^{\circ}$, and $650^{\circ} \mathrm{C}$, respectively.

The transformation temperatures of the annealed specimens were determined by differential scanning calorimetry (DSC TA-Q2000). The heating and cooling rates were set at $10^{\circ} \mathrm{C} / \mathrm{min}$. The phase transformation temperatures were characterized by a tangent line intersection method, whereas the transformation enthalpy is determined by the area under the curve.

All thermomechanical experiments were performed on a dynamic mechanical analyzer (DMA) instrument 


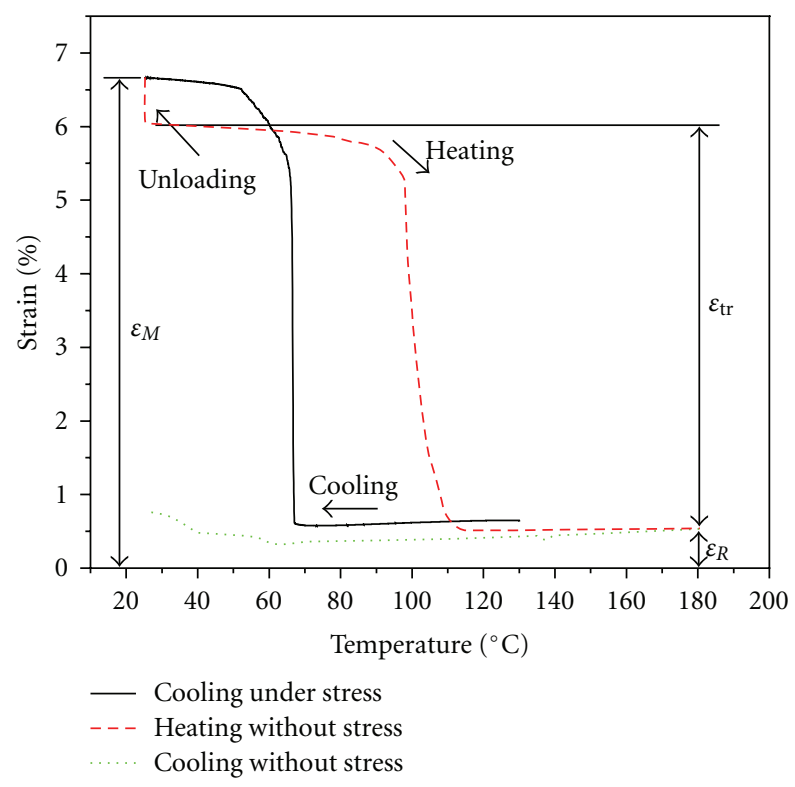

FIGURE 1: Schematic illustration of the experimental settings.

(TA Q800). Uniaxial tensile tests to failure were conducted at a strain rate of $0.5 \% / \mathrm{min}$ at a constant temperature $T=$ $25^{\circ} \mathrm{C}$.

The strain-temperature curves of annealed specimens were investigated as a function of applied stress. The experimental settings are as follows:

(1) loading the specimen at $130^{\circ} \mathrm{C}$ in the austenitic phase with a constant tensile stress,

(2) cooling the specimen from $130^{\circ} \mathrm{C}$ to $25^{\circ} \mathrm{C}$ under this constant tensile stress,

(3) unloading the sample to zero stress,

(4) heating the sample to $180^{\circ} \mathrm{C}$ followed by

(5) cooling down to $25^{\circ} \mathrm{C}$.

The heating/cooling rate is $3^{\circ} \mathrm{C} / \mathrm{min}$. A schematic illustration of the experimental settings is shown in Figure 1. Here, $\varepsilon_{\mathrm{M}}, \varepsilon_{\mathrm{tr}}$, and $\varepsilon_{\mathrm{R}}$ indicate martensitic strain, transformation strain, and residual strain, respectively.

\section{Results}

3.1. Thermal Transformation Behavior. The transformation temperatures and heats of transformation of the specimens for different annealing conditions were measured, and the results are shown in Table 1

It is seen that specimens annealed at $350^{\circ}$ and $450^{\circ} \mathrm{C}$ exhibit a two-stage $\mathrm{B} 2 \rightarrow \mathrm{R} \rightarrow \mathrm{B} 19^{\prime}$ transformation on cooling and a single-stage B19' $\rightarrow$ B2 transformation on heating. With increasing annealing temperature, the transformation temperatures increase except for Rs. Specimens annealed at $550^{\circ}$ and $650^{\circ} \mathrm{C}$ exhibit identical transformation behavior of single-stage B19' $\leftrightarrow$ B2 transformation. With increasing annealing temperature, the transformation temperatures increase slightly. It is also seen that the values of

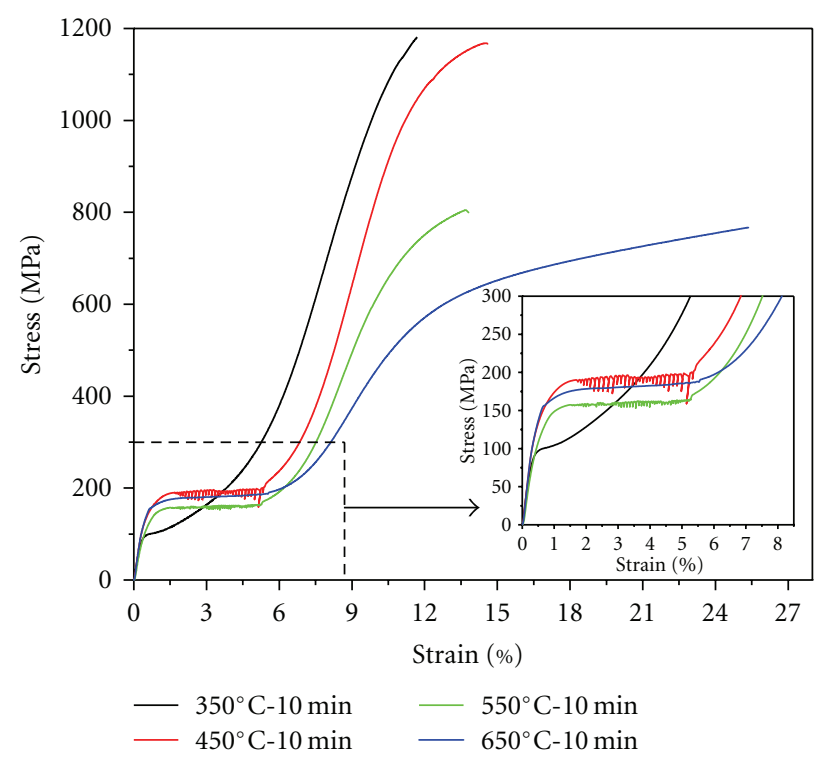

Figure 2: Stress-strain curves of annealed specimens measured at $25^{\circ} \mathrm{C}$.

heat of transformation increase with increasing annealing temperature except for $\Delta H_{\mathrm{M}}$ for the $650^{\circ} \mathrm{C}$ annealed specimen.

3.2. Tensile Tests at $25^{\circ} \mathrm{C}$. Figure 2 shows the stress-strain curves of the annealed specimens measured at $25^{\circ} \mathrm{C}$ in strain control. The inset in Figure 2 shows details of the stressstrain curves up to $300 \mathrm{MPa}$. It is seen that the values of strength for the specimens annealed at lower temperatures $\left(350^{\circ}\right.$ and $\left.450^{\circ} \mathrm{C}\right)$ are much higher than those annealed at higher temperatures $\left(550^{\circ}\right.$ and $\left.650^{\circ} \mathrm{C}\right)$. The specimen annealed at $350^{\circ} \mathrm{C}$ shows no obvious stress plateau and a sharp increase in stress with increasing strain above $3 \%$. Others show clear Lüders-type deformation over a stress plateau with plateau strain more than $5 \%$. It is interesting to note that the $450^{\circ} \mathrm{C}$ annealed specimen displays a higher and more unstable plateau stress than others. A significant amount of stress fluctuation about $40 \mathrm{MPa}$ is seen. The $550^{\circ} \mathrm{C}$ annealed specimen has a relative low plateau stress with small fluctuation about $10 \mathrm{MPa}$. The $650^{\circ} \mathrm{C}$ annealed specimen exhibits a medium and near constant plateau stress with no fluctuation.

\subsection{Transformation Strain upon Cooling at Various Constant} Stresses. Figures 3(a)-3(d) shows the strain-temperature curves of the annealed specimens under constant loads during cooling. All specimens were first heated to $130^{\circ} \mathrm{C}$ to austenite and then loaded prior to the actual cooling process. Specimens annealed at $350^{\circ}$ and $450^{\circ} \mathrm{C}$ exhibit two-step transformation upon cooling at loads of 55 and $110 \mathrm{MPa}$. The first step is related to $\mathrm{B} 2 \rightarrow \mathrm{R}$ transformation. The second step, occurring at lower temperatures, is related to $\mathrm{R} \rightarrow \mathrm{B} 19^{\prime}$ and $\mathrm{B} 2 \rightarrow \mathrm{B} 19^{\prime}$ transformation. However, R-phase transformation appears to be almost completely inhibited upon cooling at loads of 200 and $300 \mathrm{MPa}$. 
TABLE 1: The transformation temperature $\left({ }^{\circ} \mathrm{C}\right)$ and heats of transformation $(\mathrm{J} / \mathrm{g})$ obtained from the DCS curves.

\begin{tabular}{lccccccccc}
\hline Samples & $\mathrm{Rs}$ & $\mathrm{R}_{f}$ & $\Delta H_{\mathrm{R}}$ & $\mathrm{Ms}$ & $\mathrm{M}_{f}$ & $\Delta H_{\mathrm{M}}$ & $\mathrm{As}$ & $\mathrm{A}_{f}$ & $\Delta H_{\mathrm{A}}$ \\
\hline $350^{\circ} \mathrm{C}-10$ minutes & 67.12 & 50.24 & 5.788 & 32.24 & 8.54 & 12.06 & 59.60 & 79.59 & 25.26 \\
$450^{\circ} \mathrm{C}-10$ minutes & 62.19 & 58.69 & 7.593 & 46.18 & 37.14 & 15.79 & 78.61 & 88.85 & 25.93 \\
$550^{\circ} \mathrm{C}-10$ minutes & - & - & - & 67.60 & 60.95 & 31.68 & 92.36 & 105.34 & 26.43 \\
$650^{\circ} \mathrm{C}-10$ minutes & - & - & - & 71.19 & 62.99 & 29.94 & 95.33 & 113.28 & 28.70 \\
\hline
\end{tabular}

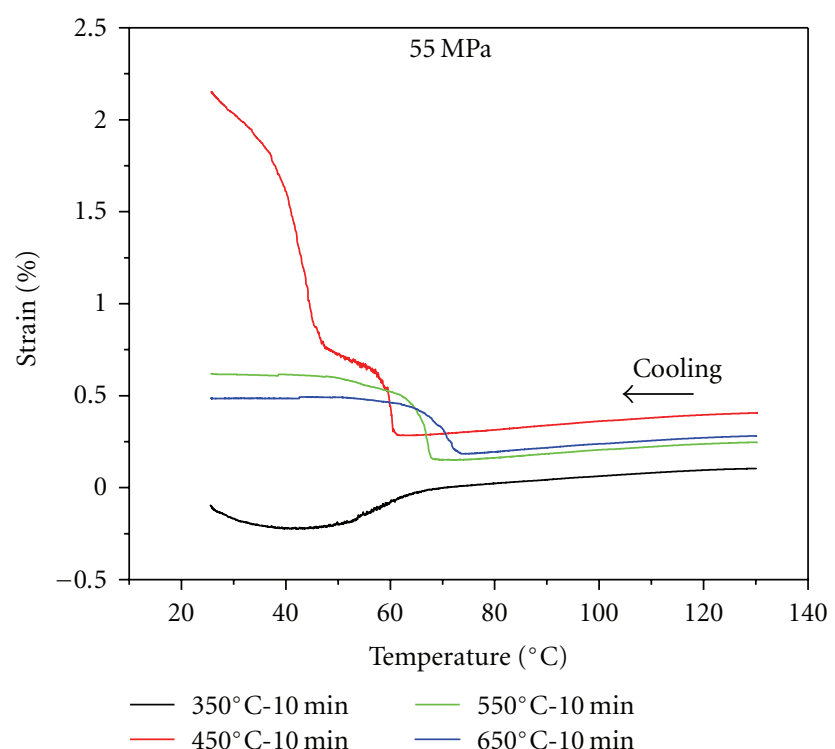

(a)

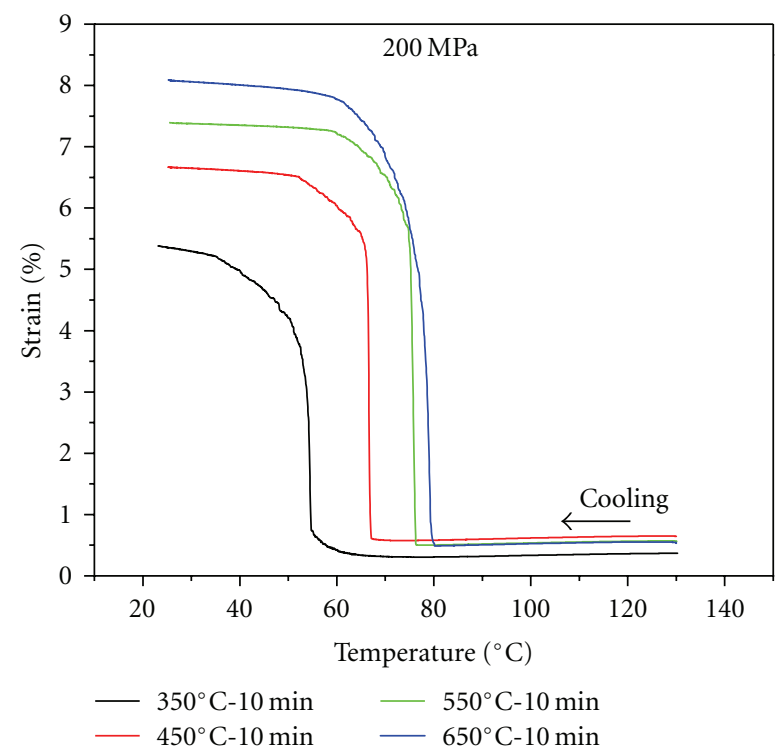

(c)

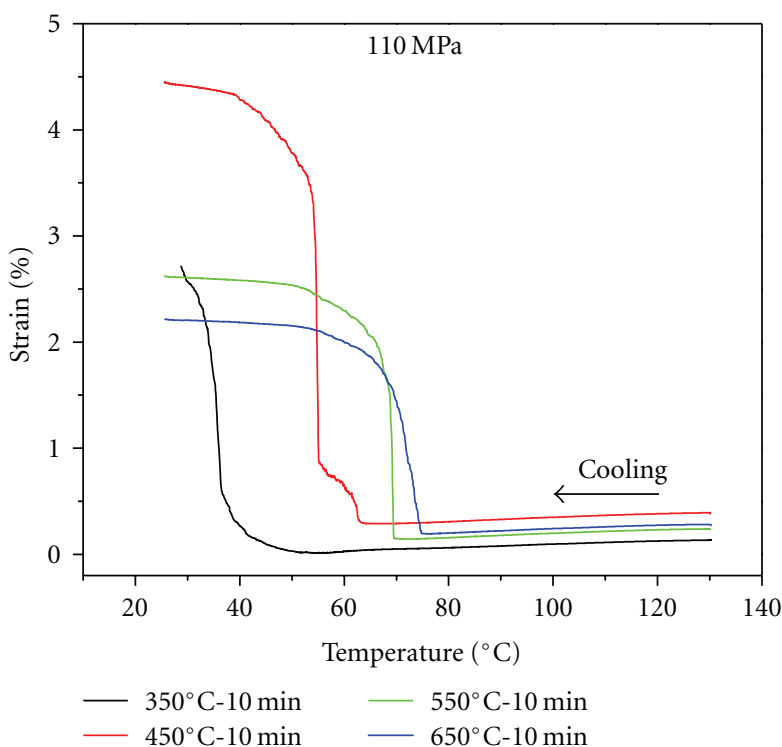

(b)

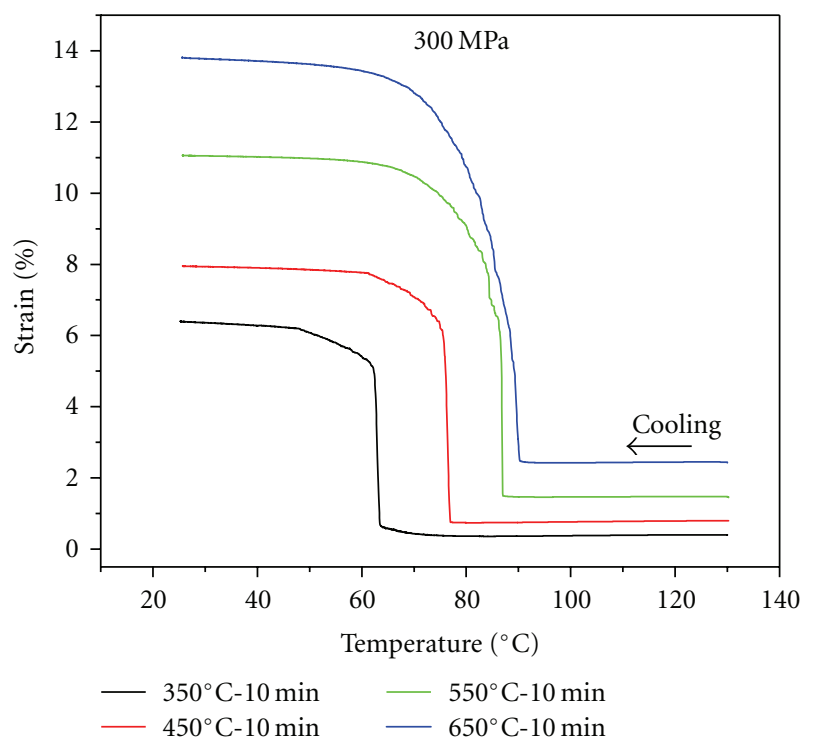

(d)

FIGURE 3: Strain-temperature curves upon cooling under various constant applied stresses.

It is seen that the strain slowly increases at lower stress levels but drastically increases at higher stress levels. The martensitic strain of the specimen annealed at $350^{\circ} \mathrm{C}$ is zero at $25^{\circ} \mathrm{C}$ when cooling under a constant stress of $55 \mathrm{MPa}$.
Figure 4 shows the variation of transformation temperature Ms as a function of applied stress for the annealed specimens. The transformation temperatures were determined by a tangent line intersection method from curves in Figure 3. It is seen that the Ms temperatures increase with 


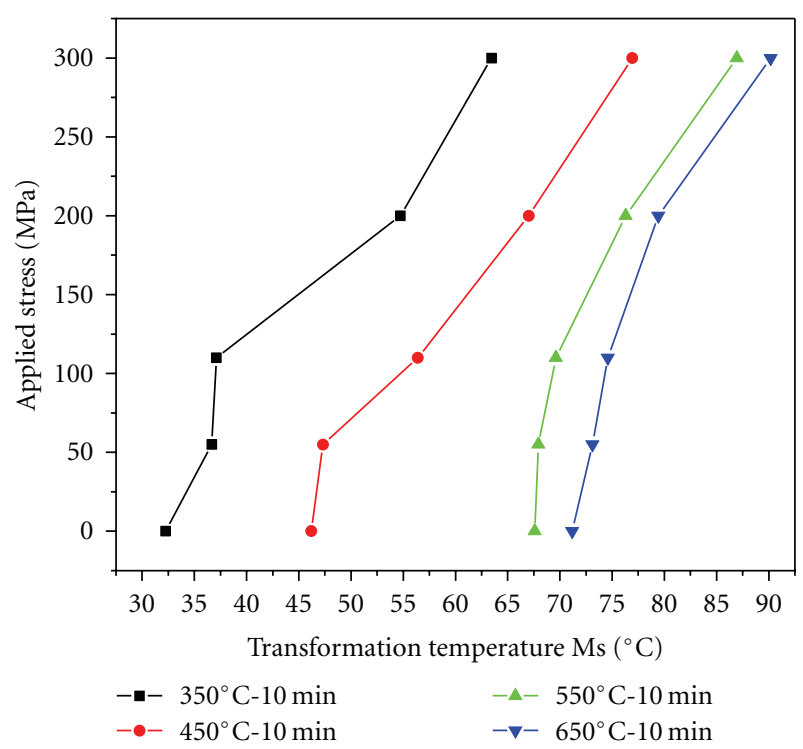

FIGURE 4: Effect of applied stress on the transformation temperature Ms.

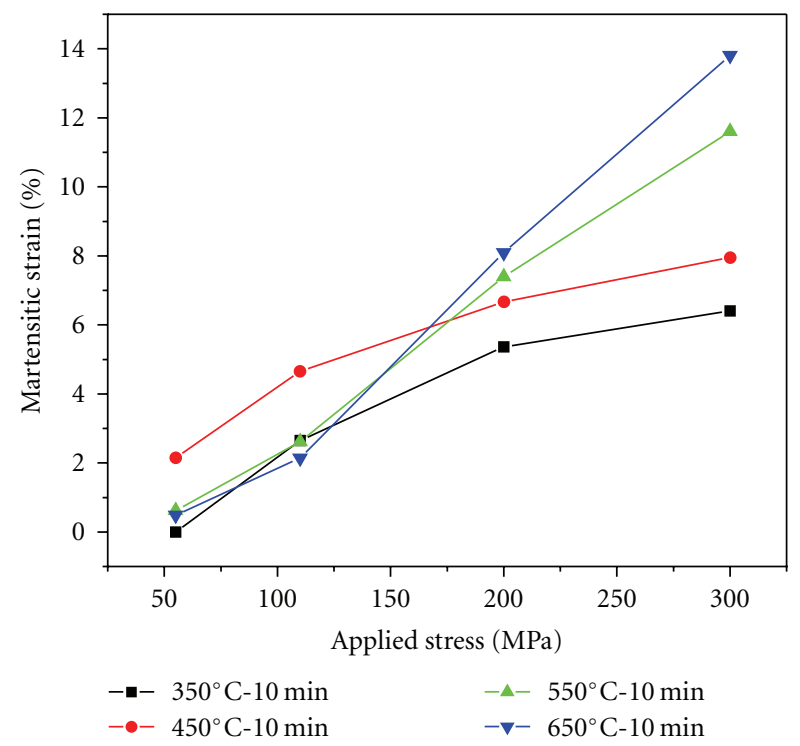

FIGURE 5: Effect of applied stress on the martensitic strain $\varepsilon_{M}$.

increasing applied stress for all specimens. This is closely in-line with the Clausius-Clapeyron relationship that as the applied external stress increases so do the transformation temperatures [17].

Figure 5 shows the effect of applied stress on the martensitic strain $\varepsilon_{\mathrm{M}}$. For all samples, the martensitic strain increases with increasing applied stress. The increase is noticeably more pronounced in samples annealed at higher temperature.

Figure 6 shows the effect of annealing temperature on the martensitic strain $\varepsilon_{M}$, a different manner of presenting the results in Figure 5. It is worth noting that the martensitic strains at loads of 55 and $110 \mathrm{MPa}$ increase with increasing annealing temperature up to $450^{\circ} \mathrm{C}$ and decrease when

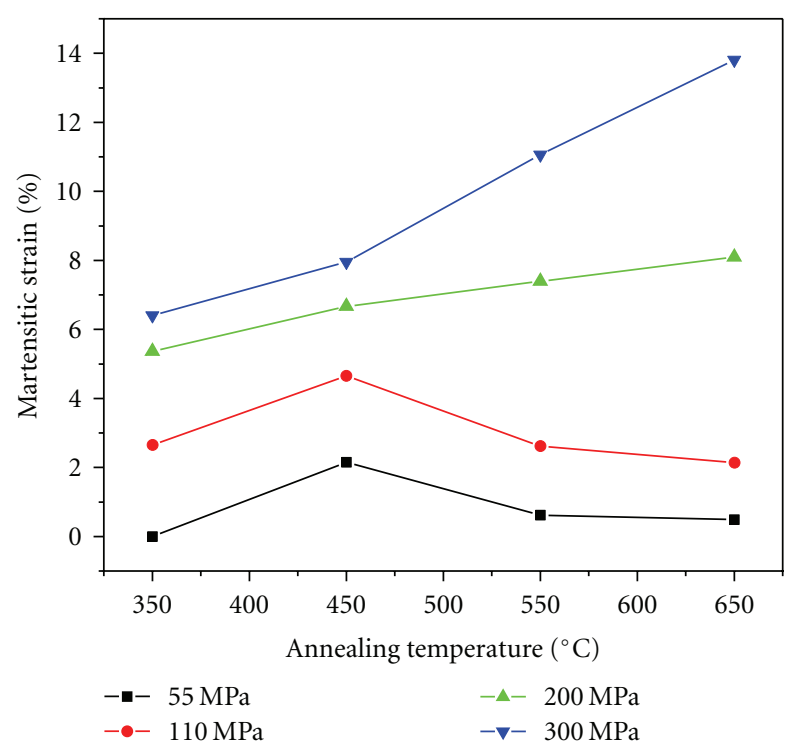

FIGURE 6: Effect of annealing temperature on the martensitic strain $\varepsilon_{M}$.

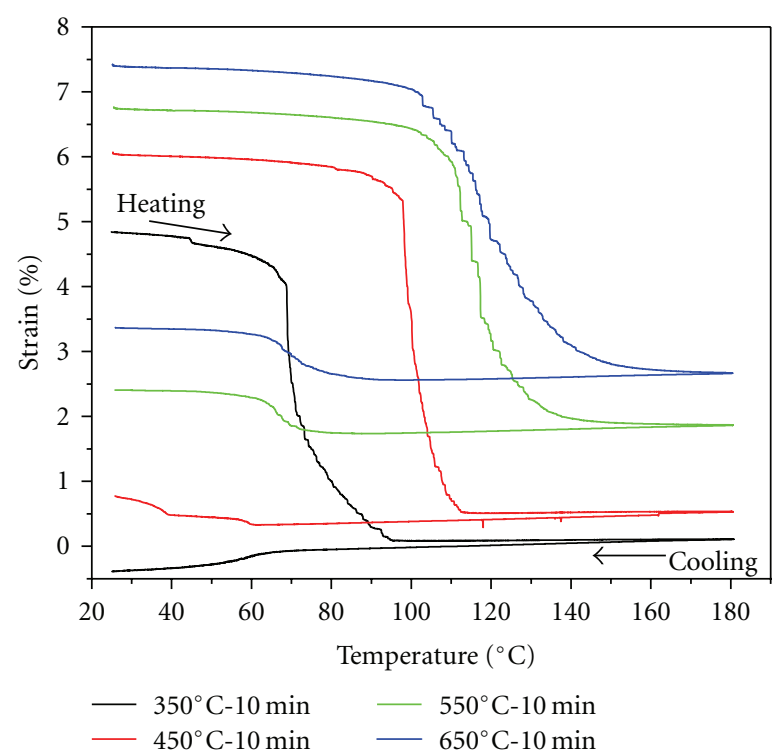

FIGURE 7: Representative strain-temperature curves measured during free shape recovery after cooling under a constant stress of $200 \mathrm{MPa}$.

annealed above $450^{\circ} \mathrm{C}$. The martensitic strains at loads of 200 and $300 \mathrm{MPa}$ monotonically increase with increasing annealing temperature, and the increase is noticeably more pronounced for higher loads.

3.4. Free Shape Recovery. Figure 7 shows representative strain-temperature curves measured during free shape recovery after cooling at constant stress of $200 \mathrm{MPa}$. For $550^{\circ}$ and $650^{\circ} \mathrm{C}$ annealed specimens the austenite was not fully recovered at the highest temperature, possibly due to the development of microplasticity generated during the first cooling from the austenite under load. 


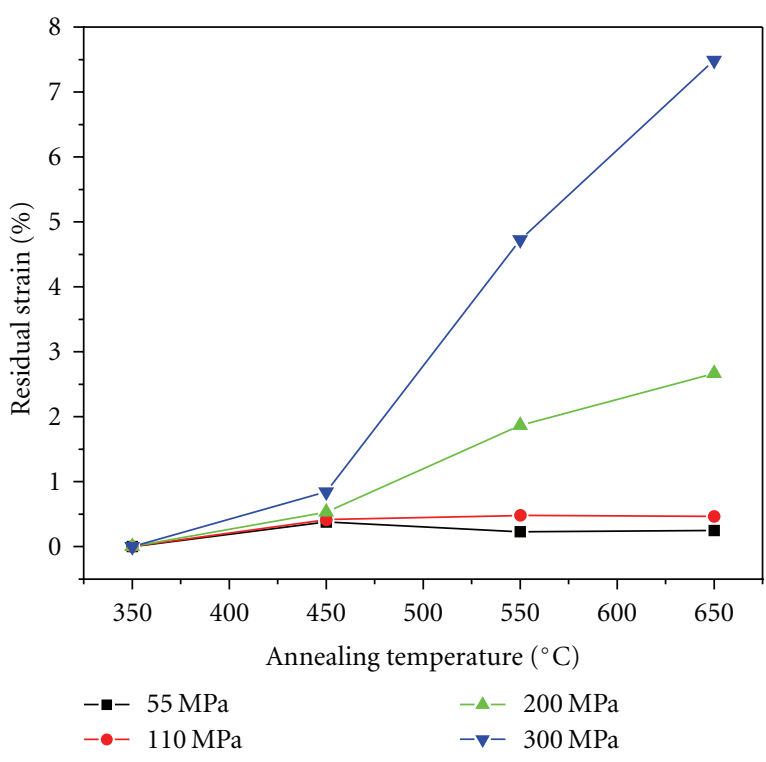

FIGURE 8: Effect of annealing temperature on the residual strain $\varepsilon_{R}$.

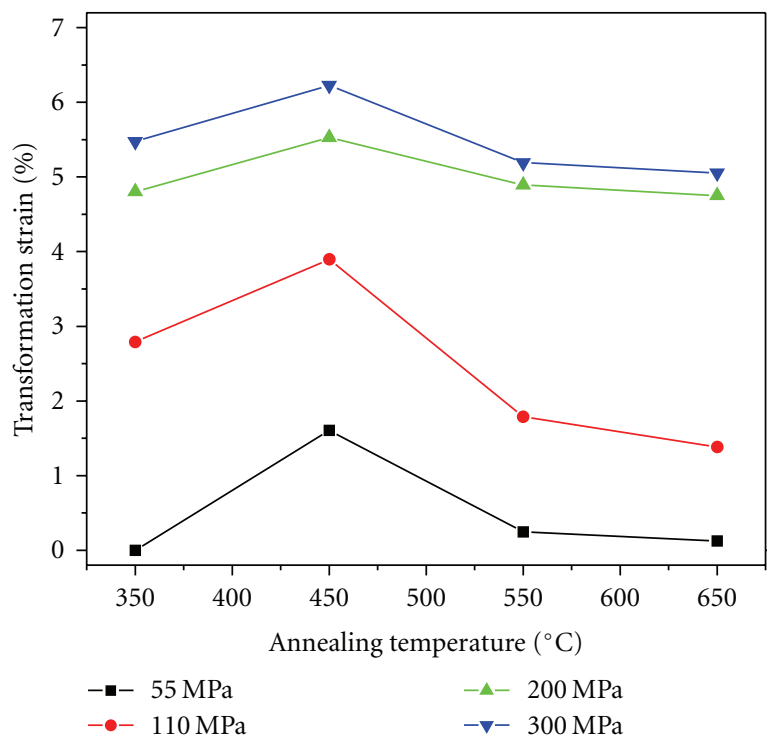

FIGURE 9: Effect of annealing temperature on the transformation strain $\varepsilon_{t r}$.

Figure 8 shows the effect of annealing temperature on the residual strain $\varepsilon_{R}$. The tendency is similar to the effect of annealing temperature on the martensitic strain $\varepsilon_{M}$, as shown in Figure 6. It is interesting to note that, even at high applied stress, the martensitic strain of the $350^{\circ} \mathrm{C}$ annealed specimen can completely recover upon heating above the austenite finish temperature. Thus, the residual strain is nonexistent in the strain-temperature curves.

Figure 9 shows the effect of annealing temperature on the transformation strain $\varepsilon_{\text {tr }}$. It is seen that, for all samples, the transformation strain increases with increasing applied stress. It is worth noting that, regardless of the applied stress level, the transformation strain increases with increasing annealing temperature up to $450^{\circ} \mathrm{C}$ and decreases when annealed above $450^{\circ} \mathrm{C}$. The decrease is noticeably more pronounced at lower applied stresses.

\section{Discussion}

In this study the materials were not deformed in the martensite condition. We start cooling the specimens from austenite under a constant applied stress. The results show that the martensitic strain $\varepsilon_{\mathrm{M}}$, transformation strain $\varepsilon_{\mathrm{tr}}$, and residual strain $\varepsilon_{R}$ developed during cooling and heating are strongly affected by annealing and/or applied stress. This phenomenon could be related to the number and distribution of dislocations and textures of the materials.

The previous studies have shown that the texture orientation significantly influences the stress-strain curve and shape memory strain of NiTi SMAs [18-20]. Polycrystalline NiTi with a high density of grains oriented with a $\langle 111\rangle$ axis parallel to the loading direction will generally demonstrate large recoverable transformation strains in tension. It is known that a cold-worked NiTi alloy usually has a strong $\langle 111\rangle$ texture. When the annealing temperature is below the recrystallization temperature, annealing causes recovery to occur without changing the crystalline orientation distribution appreciably. So that the deformation texture remains and affects the shape memory characteristics of the colddrawn wire [19]. The degree of texturing was much less in the higher temperature annealing condition. From this point of view, the recoverable transformation strain could decrease with increasing annealing temperature.

It is also well known that cold working introduces high density of dislocations in NiTi alloys, which increases the strength but decreases the ductility. Also the dislocations act to inhibit the martensitic transformation [21]. Annealing induces annihilation of the dislocations and recrystallization of the cold-worked specimen. The higher the annealing temperature, the more the dislocations are rearranged and annihilated. Therefore, with increasing annealing temperature, the dislocation density decreases, which could cause an increase in the recoverable transformation strain.

In this study, specimens annealed at $350^{\circ}$ and $450^{\circ} \mathrm{C}$ exhibited two-stage B2 $\rightarrow \mathrm{R} \rightarrow \mathrm{B} 19^{\prime}$ transformations on cooling, implying that the samples were partially annealed without recrystallization. For the specimen annealed at $350^{\circ} \mathrm{C}$, the dislocation density and the strength were high, which inhibits the free propagation of martensitic variants across neighboring grains, so the martensitic strain $\varepsilon_{\mathrm{M}}$, transformation strain $\varepsilon_{\mathrm{tr}}$, and residual strain $\varepsilon_{\mathrm{R}}$ are small. Annealing at $450^{\circ} \mathrm{C}$ causes a decrease in dislocation density, which leads to less resistance to martensitic transformation. On the other hand, the degree of the texturing is still high, so the largest transformation strain $\varepsilon_{\text {tr }}$ was obtained at all stress levels, as shown in Figure 9. At the same time, the residual strain $\varepsilon_{R}$ was relatively small, as shown in Figure 8 . When annealing above the recrystallization temperature, the dislocation density and the strength decrease largely. In this case, the microplastic deformation was easily induced during the martensitic transformation under loads, which leads to the decrease in the transformation strain $\varepsilon_{\text {tr }}$ and 
the increase in the residual strain $\varepsilon_{R}$, as shown in Figures 8 and 9. Interestingly, a slightly smaller residual strain $\varepsilon_{\mathrm{R}}$ in $550^{\circ}$ and $650^{\circ} \mathrm{C}$ annealed specimens was observed under the stress levels of 55 and $110 \mathrm{MPa}$. One possible reason for this is that only the grains with the most favorable orientation transform into stress-induced martensite under the stress levels of 55 and $110 \mathrm{MPa}$, and the number of these grains decreases with increasing annealing temperature. This phenomenon needs further investigation.

\section{Conclusions}

In this paper we examined the influence of annealing on strain-temperature behavior of cold-worked NiTi wires under constant tensile stresses. The results show that a large martensitic strain can be reached, even though the applied stress is below the plateau stress of the martensite phase. The martensitic strain is strongly affected by annealing temperature and applied stress. The strain increases with increasing applied stress for all annealing conditions. At higher applied stress the martensitic strain increases with increasing annealing temperature; at lower applied stress the value increases when annealing until $450^{\circ} \mathrm{C}$ and then decreases when annealing above $450^{\circ} \mathrm{C}$. The same tendency is also seen in the variation of residual strain with annealing temperature. Regardless of the level of applied stress, transformation strain increases first and then decreases with increasing annealing temperature.

\section{Acknowledgment}

The authors gratefully acknowledge the financial support from FWO-project G-0652.05.

\section{References}

[1] J. Van Humbeeck, "Non-medical applications of shape memory alloys," Materials Science and Engineering A, vol. 273-275, pp. 134-148, 1999.

[2] K. Otsuka and X. Ren, "Recent developments in the research of shape memory alloys," Intermetallics, vol. 7, no. 5, pp. 511528, 1999.

[3] Y. Liu and P. G. McCormick, "Thermodynamic analysis of the martensitic transformation in NiTi-I. Effect of heat treatment on transformation behaviour," Acta Metallurgica Et Materialia, vol. 42, no. 7, pp. 2401-2406, 1994.

[4] Y. Liu and S. P. Galvin, "Criteria for pseudoelasticity in nearequiatomic NiTi shape memory alloys," Acta Materialia, vol. 45, no. 11, pp. 4431-4439, 1997.

[5] X. Huang and Y. Liu, "Effect of annealing on the transformation behavior and superelasticity of NiTi shape memory alloy," Scripta Materialia, vol. 45, no. 2, pp. 153-160, 2001.

[6] D. Treppmann, E. Hornbogen, and D. Wurzel, "The effect of combined recrystallization and precipitation processes on the functional and structural properties in NiTi alloys," Journal de Physique IV, vol. 5, pp. 569-574, 1995.

[7] D. A. Miller and D. C. Lagoudas, "Influence of cold work and heat treatment on the shape memory effect and plastic development of NiTi," Materials Science and Engineering A, vol. 308 , no. 1-2, pp. 161-175, 2001.
[8] A. K. Srivastava, D. Schryvers, and J. Van Humbeeck, "Grain growth and precipitation in an annealed cold-rolled $\mathrm{NiTi}$ alloy," Intermetallics, vol. 15, no. 12, pp. 1538-1547, 2007.

[9] I. Y. Khmelevskaya, "Effect of initial strengthening on recovery stress generation and isothermal relaxation processes in TiNi alloys," Journal de Physique IV, vol. 11, pp. 41-46, 2001.

[10] X. J. Yan and J. Van humbeeck, "Influence of annealing on recovery stress of cold-worked NiTi wire," Functional Materials Letters, vol. 2, no. 2, pp. 1-6, 2009.

[11] J. Van Humbeeck, "Damping capacity of thermoelastic martensite in shape memory alloys," Journal of Alloys and Compounds, vol. 355, no. 1-2, pp. 58-64, 2003.

[12] Y. Liu, J. Van Humbeeck, R. Stalmans, and L. Delaey, "Some aspects of the properties of NiTi shape memory alloy," Journal of Alloys and Compounds, vol. 247, no. 1-2, pp. 115-121, 1997.

[13] P. Sittner, Y. Liu, and V. Novak, "On the origin of Lüderslike deformation of NiTi shape memory alloys," Journal of the Mechanics and Physics of Solids, vol. 53, no. 8, pp. 1719-1746, 2005.

[14] A. S. Mahmud, H. Yang, S. Tee, G. Rio, and Y. Liu, "Effect of annealing on deformation-induced martensite stabilisation of NiTi," Intermetallics, vol. 16, no. 2, pp. 209-214, 2008.

[15] J. E. Schaffer and D. L. Plumley, "Fatigue performance of nitinol round wire with varying cold work reductions," Journal of Materials Engineering and Performance, vol. 18, no. 5-6, pp. 563-568, 2009.

[16] X. J. Yan, D. Z. Yang, and X. P. Liu, "Influence of heat treatment on the fatigue life of a laser-welded NiTi alloy wire," Materials Characterization, vol. 58, no. 3, pp. 262-266, 2007.

[17] K. Wada and Y. Liu, "Shape recovery of NiTi shape memory alloy under various pre-strain and constraint conditions," Smart Materials and Structures, vol. 14, no. 5, pp. S273-S286, 2005.

[18] Y. Liu, Z. L. Xie, J. Van Humbeeck, and L. Delaey, "Effect of texture orientation on the martensite deformation of NiTi shape memory alloy sheet," Acta Materialia, vol. 47, no. 2, pp. 645-660, 1999.

[19] S. Miyazaki, V. H. No, K. Kitamura, A. Khantachawana, and H. Hosoda, "Texture of Ti-Ni rolled thin plates and sputterdeposited thin films," International Journal of Plasticity, vol. 16, no. 10, pp. 1135-1154, 2000.

[20] P. Sittner, D. Neov, P. Lukas, and D. M. Toebbens, "Neutron diffraction studies of the stress effect on texture transformations in NiTi shape memory alloys," Journal of Neutron Research, vol. 12, no. 1-3, pp. 15-20, 2004.

[21] D. Treppmann and E. Hornbogen, "On the influence of thermomechanical treatments on shape memory alloys," Journal de Physique IV, no. 7, pp. C5-211-C5-220, 1997. 

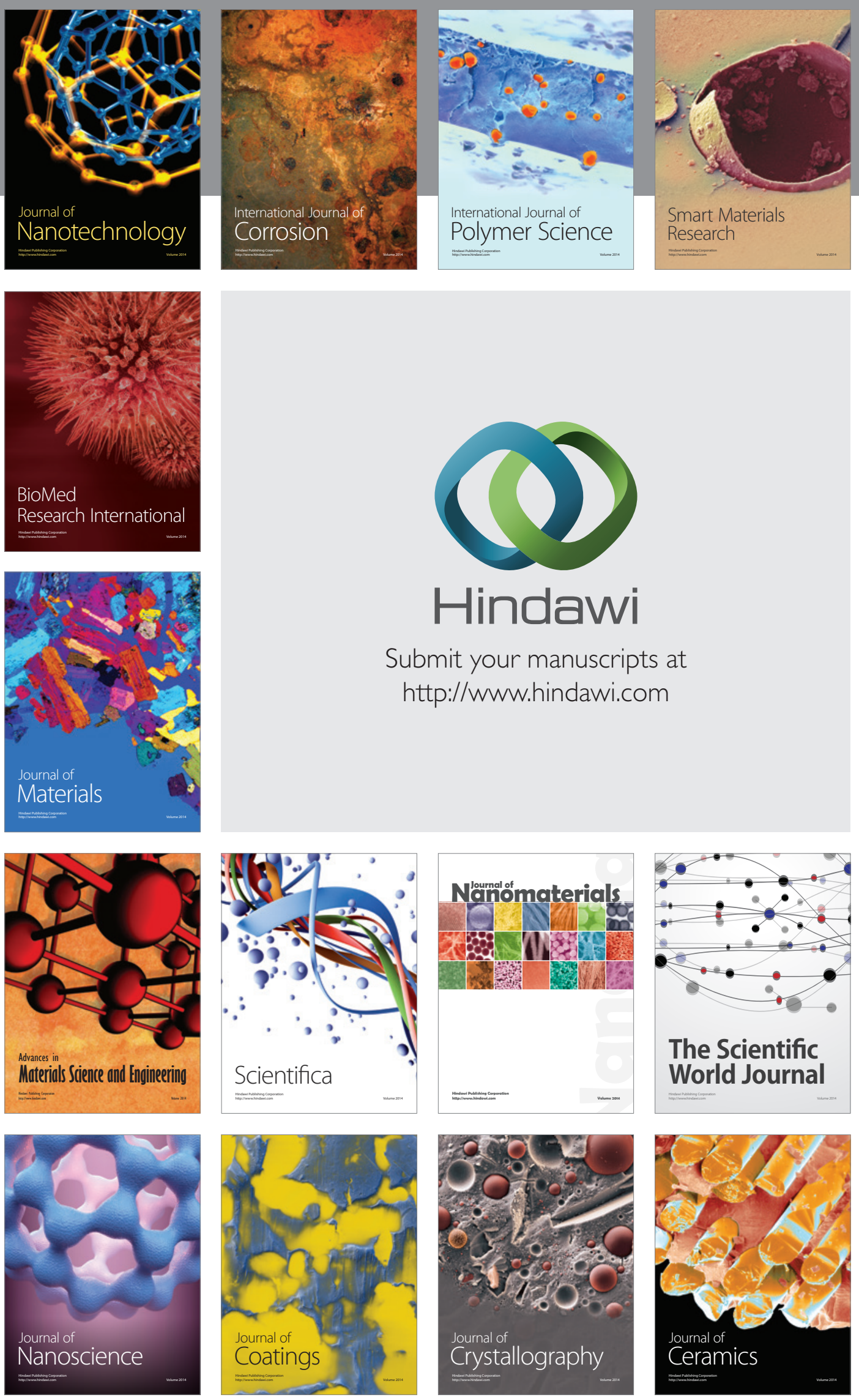

The Scientific World Journal

Submit your manuscripts at

http://www.hindawi.com

\section{World Journal}

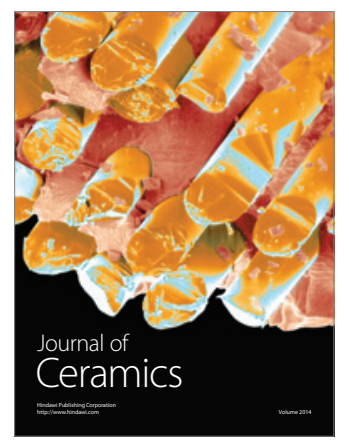

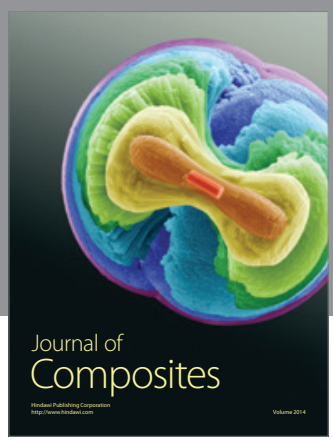
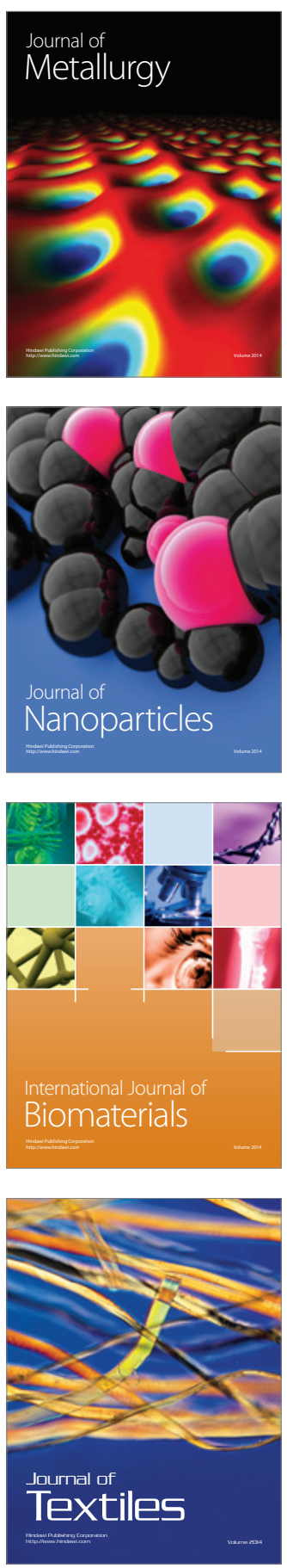